\title{
Shaking Table Test and Numerical Verification for Free Ground Seismic Response of Saturated Soft Soil
}

\author{
Xuelei Cheng $\mathbb{D}^{1},{ }^{1}$ Chunyi Cui ${ }^{D},{ }^{1}$ Zongguang Sun, ${ }^{1}$ Jinhong Xia, ${ }^{2}$ and Guangbing Wang ${ }^{1}$ \\ ${ }^{1}$ Transportation Engineering College, Dalian Maritime University, Dalian 116026, Liaoning, China \\ ${ }^{2}$ School of Civil Engineering and Architecture, Xinxiang University, Xinxiang 453003, China \\ Correspondence should be addressed to Xuelei Cheng; chengxuelei@dlmu.edu.cn
}

Received 7 June 2018; Revised 11 August 2018; Accepted 2 September 2018; Published 28 October 2018

Academic Editor: Mohammad A. Hariri-Ardebili

Copyright (c) 2018 Xuelei Cheng et al. This is an open access article distributed under the Creative Commons Attribution License, which permits unrestricted use, distribution, and reproduction in any medium, provided the original work is properly cited.

\begin{abstract}
This paper investigates shaking table test (1g) and numerical simulation (fully coupled) of vertically propagating shear waves for saturated soft free field. A large-scale shaking table model test was performed to study seismic response characteristics of saturated soft soil free field. According to test results of seismic response features of free field system in saturated soft soil, the free field nonlinearity fully coupled numerical model of dynamical effective stress of saturated soft soil was established using OpenSEES, based on the $u$ - $p$ formulations of dynamic consolidation equation as well as effective stress solution method for saturated twophase media. The numerical simulation of the free field seismic response of saturated soft soil under various test conditions was performed and the calculated results were compared with the shaking table test results. The results show the following. (1) With the increase of input ground motion intensity, the characteristic frequency of the saturated soft free ground decreases and the damping ratio increases gradually. (2) The saturated soft soil ground has short period filtering and long period amplification effect on the horizontal input seismic loads. The failure foundation takes on the isolation and shock absorption under strong ground motions. (3) The peak pore pressure ratio of the saturated soft soil ground is located in the shallow buried soil layer, and with the increase of the input ground motion intensity, the advantage of dynamic pore pressure ratio in this area is gradually weakened. (4) The numerical simulation results are consistent with the results of the shaking table test. This fully coupled effective stress numerical method can reasonably simulate the seismic response characteristics of free field in saturated soft soil, which lay the foundation for other more complex parameter extrapolation models of saturated soft soil sites. This research can provide the necessary technical experience for experimental study on non-free field.
\end{abstract}

\section{Introduction}

Soft soil is widely distributed in China. As numerous studies suggest, soft ground can cause greater seismic damage of underground structures. For instance, Dakai subway station was destroyed in 1995 Hanshin earthquake, which consumed 10 billion yen to repair [1, 2] (Kawashima, 2000; Hashash, 2001). The design standards for underground structure in soft ground are behind that of the liquefiable sand ground, which only gives some qualitative and general provisions [3] (Yamashita, 2012). Therefore, there is a lack of more in-depth and systematic research, and more extensive and intensive studies are still needed on seismic disaster mechanism in saturated soft soil foundation.
Generally, theoretical analysis method, numerical simulation method, and model test method are three major research methods in seismic responses of underground structure. Plenty of theoretical results have not been validated since the complexity of soft soil. Therefore, it is difficult to guide engineering design. Since shaking table test has no "Coriolis effect", it is an effective method to study the seismic response of free field. Model test should be necessarily performed to verify the results of theoretical research. Some scholars have studied the seismic responses of underground structures embedded in soft soil sites. Turan [4] (2009) investigates seismic soil-structure interaction of building with embedded basement stories founded in unsaturated clayey sons by small shaking table test. Chen et al. $[5,6](2010$, 
2012) conduct on scaled utility tunnel models embedded in unsaturated clay soil of Shanghai with and without construction joints under nonuniform input earthquake wave excitation by a series of shaking table tests and numerical simulation method. Chen et al. [7] (2015) investigate the damage mechanisms of a subway structure in soft soil while experiencing strong ground motions by shaking table test. Chen et al. [8] (2016) investigate the effect of pulse-like ground motion on a multistory subway station embedded in unsaturated soft soil with a series of shaking table tests. Further, Wang et al. [9] (2013) investigate the dynamic through-soil interaction between underground station and nearby pile supported structure on viscous-elastic soil layer under vertically incident $S$ wave with numerical method. Zhuang et al. [10] (2015) estimate the earthquake damage of a large subway station built in soft ground with the total stress numerical simulation method. Huang et al. [11] (2017) investigate the nonlinear responses of the tunnels within surface normal fault ground under obliquely incident $\mathrm{P}$ waves based on the total stress numerical simulation method. The above research is important to understand the seismic response of underground structure embedded in soft ground. From the research of shaking table test performed, underground structure is mostly embedded in unsaturated soft soil, and the numerical simulation methods are mostly based on the total stress analysis methods. The total stress method can not consider the effect of pore pressure, which is inconsistent with the real situation. It is necessary to consider the influence of pore pressure in soft soil sites with the dynamic effective stress method [12] (Chen, 2011). The shaking table test has been rarely performed for saturated soft ground and the seismic response numerical simulation of saturated soft ground has been also rarely analyzed with test verification. Besides, in order to further consider the coupling effect of pore pressure and soil skeleton in the seismic dynamic response analysis of underground structures embedded in soft soil, Zhou et al. [13] (2004) carry out soft soil indoor dynamic test and adopted the two-dimensional decoupling finite element effective stress dynamic response analysis based on Hardin dynamic viscoelastic model. Azadi et al. [14] (2010), based on the decoupling two-dimensional effective stress dynamic finite element method, discuss the influence rule of large deformation of the site on the dynamic deformation of shallow buried underground structures, while the decoupling effective stress dynamic calculation method based on the pore pressure stress (strain) model has certain limitation for describing the deformation characteristics of pore pressure and soil skeleton under seismic loads [15-17] (Schrefler, 2001; Luan, 2009; Ghassemi, 2010). The fully coupled effective stress dynamic calculation method should be applied in seismic dynamic response analysis of the underground structure embedded in saturated soft soil ground.

The study on the seismic response characteristics of free ground is the premise of underground structure embedded in soft soil. In this regard, a large-scale shaking table test was performed to study seismic response characteristics of saturated soft free field ground. The nonlinearity coupled numerical model of dynamical effective stress of saturated soft free foundation was established using OpenSEES, based

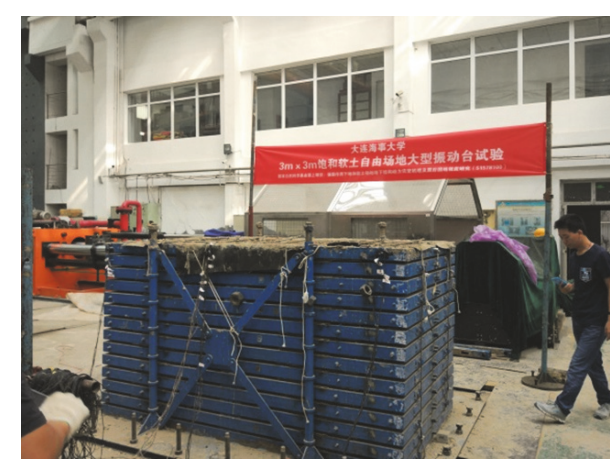

FIgURE 1: The laminar shear model box.

on the $u$ - $p$ formulations of dynamic consolidation equation and effective stress solution method for saturated two-phase media. And the test results are compared with the numerical simulation results to verify the accuracy of this numerical simulation method.

\section{Shaking Table Test}

Shaking table test of saturated soft free field was performed in the Key Laboratory of Urban Security and Disaster Engineering in Beijing University of Technology. The table is sized as $3 \mathrm{~m} \times 6 \mathrm{~m}$ in plane. The maximum acceleration of shaking table is $1 \mathrm{~g}$ with full load (10 tons), in which $\mathrm{g}$ denotes the acceleration resulting from gravity in $\mathrm{m} / \mathrm{s}^{2}$. The frequency of input wave ranges from $0.1 \mathrm{~Hz}$ to $50 \mathrm{~Hz}$. The maximum displacement of shaking reaches up to $\pm 125 \mathrm{~mm}$.

2.1. Model Box Design. The box is $2.50 \mathrm{~m}$ long $(x) \times 1.40 \mathrm{~m}$ width $(y) \times 1.38 \mathrm{~m}$ height $(z)$ in overall dimension, as shown in Figure 1. It encompasses 14 steel frames stacked on box, numbered as No. 1-14 from bottom to top. Each frame is made of steel pipe with a rectangular cross-section size of $80 \mathrm{~mm}$ $\times 80 \mathrm{~mm} \times 3 \mathrm{~mm}$ (width $\times$ height $\times$ thickness). Damping coefficient reaches up to $200 \mathrm{~N} \cdot \mathrm{s} / \mathrm{m}$, and spring stiffness coefficient reaches up to $2250 \mathrm{~N} / \mathrm{m}$. The interlayer distance is $20 \mathrm{~mm}$ between steel pipes. The natural frequency of the empty box is $1.28 \mathrm{~Hz}$. The natural frequency of the model box filled with saturated soft soil is $8.85 \mathrm{~Hz}$. The natural frequency of the empty box is different from the model natural frequency of the filled box model with saturated soft soil. Therefore, the resonance phenomenon cannot occur in this experiment.

2.2. Similarity Ratio Design. In accordance with Bukinghan $\pi$ theorem, the shear wave velocity, density, and (gravity) acceleration are selected as the basic physical quantity for soil similar ratio, and the specific similarities are listed in Table 1 . The similarity constant is the ratio between the model physical quantity and the prototype physical quantity.

2.3. Model Soil Preparation. The soft clay was from Beijing, which should be dried and cleared before testing. The soil was placed into the shear box layer by layer and each layer was 
TABLE 1: Scale relations and ratio of model system.

\begin{tabular}{|c|c|c|c|c|}
\hline Item Type & Physical quantity & Dimension & Similarity relation & Similarity ratio \\
\hline \multirow{2}{*}{ Geometrical characteristics } & Length $(l)$ & {$[L]$} & $S_{l}$ & $1: 4$ \\
\hline & Linear Displacement $(r)$ & {$[L]$} & $S_{r}=S_{l}$ & $1: 4$ \\
\hline \multirow{2}{*}{ Material characteristics } & $\operatorname{Density}(\rho)$ & {$\left[M L^{-3}\right]$} & $S_{\rho}=S_{\sigma} \cdot\left(S_{a} \cdot S_{l}\right)^{-1}$ & $1: 1$ \\
\hline & $\operatorname{Velocity}\left(v_{s}\right)$ & {$\left[L T^{-1}\right]$} & $S_{v}=\left(S_{a} \cdot S_{l}\right)^{0.5}$ & $1: 2$ \\
\hline \multirow{5}{*}{ Dynamic characteristics } & Pore pressure $(u)$ & {$\left[M L T^{-2}\right]$} & $S_{u}=S_{\sigma}$ & $1: 4$ \\
\hline & Time $(t)$ & {$[T]$} & $S_{t}=\left(S_{l} / S_{a}\right)^{0.5}$ & $1: 2$ \\
\hline & Frequency $(f)$ & {$\left[T^{-1}\right]$} & $S_{f}=\left(S_{l} / S_{a}\right)^{-0.5}$ & $2: 1$ \\
\hline & $\operatorname{Acceleration}(a)$ & {$\left[L T^{-2}\right]$} & $S_{a}$ & 1 \\
\hline & $\operatorname{Stress}(\sigma)$ & {$\left[M L^{-1} T^{-2}\right]$} & $S_{\sigma}$ & $1: 4$ \\
\hline
\end{tabular}

TABLE 2: Soil physical and mechanical parameters.

\begin{tabular}{lcccccc}
\hline $\begin{array}{l}\text { Density } \\
\mathrm{kg} \cdot \mathrm{m}^{-3}\end{array}$ & $\begin{array}{c}\text { Liquidity } \\
\text { index }\end{array}$ & $\begin{array}{c}\text { Plasticity } \\
\text { index }\end{array}$ & $\begin{array}{c}\text { Permeability } \\
\text { coefficient } \\
\mathrm{m} \cdot \mathrm{s}^{-1}\end{array}$ & Soil Porosity & $\begin{array}{c}\text { Shear wave } \\
\text { velocity } \\
\mathrm{m} \cdot \mathrm{s}^{-1}\end{array}$ & $\begin{array}{c}\text { Sohesion } \\
\mathrm{kPa}\end{array}$ \\
\hline 1700 & 1.48 & 16.63 & $3 \times 10^{-7}$ & 0.6 & 50 & $\begin{array}{c}\text { gravity of soil } \\
\text { particle } \\
\mathrm{g} \cdot \mathrm{cm}^{-3}\end{array}$ \\
\hline
\end{tabular}

TABLE 3: Type of sensors used in shaking table test.

\begin{tabular}{|c|c|c|c|c|c|c|}
\hline No. & Sensor type & Code & Quantity & Model & Application & Remarks \\
\hline 1 & Accelerometer & A & 16 & KD1050L & $\begin{array}{l}\text { Monitoring acceleration } \\
\text { of shaking table and } \\
\text { measuring point } \\
\text { acceleration response in } \\
\text { soil }\end{array}$ & \\
\hline 2 & Piezometer & $\mathrm{W}$ & 16 & DYS & $\begin{array}{l}\text { Monitoring dynamic } \\
\text { pore pressure increasing } \\
\text { of measuring point in } \\
\text { soil }\end{array}$ & $\begin{array}{c}\text { Strain } \\
\text { miniature } \\
\text { piezometer }\end{array}$ \\
\hline 4 & $\begin{array}{c}\text { Laser } \\
\text { displacement } \\
\text { sensor }\end{array}$ & $\mathrm{D}$ & 2 & $\begin{array}{l}\text { Micro- } \\
\text { Epsilon } \\
\text { 1420-200 }\end{array}$ & $\begin{array}{l}\text { Monitoring settlement of } \\
\text { model ground surface } \\
\text { under earthquake load }\end{array}$ & \\
\hline
\end{tabular}

with the thickness of $20 \mathrm{~cm}$. At the same time, soil samples were measured to ensure the soil density of each layer valued the same. After paving each layer of soil, the surface of soil was leveled with a wooden board. The model soil was enabled to stand $72 \mathrm{~h}$ to make the model soil fully consolidated. The average temperature is $30^{\circ} \mathrm{C}$, and the average relative humidity is $70 \%$ in the laboratory in Beijing in August. In order to fully saturate and consolidate the model foundation, the surface of model foundation was covered with a layer water of $5 \mathrm{~cm}$ thickness and covered with plastic paper for moisturizing. The surface water should be drained before test. Table 2 lists the test result of soil properties.

2.4. Sensor Arrangement. Table 3 lists the type of sensors. The sensor layout of the primary observation section and subobservation section as presented in Figure 2. The flexible chain sensor placement technique was used in this experiment to increase the packing efficiency of soil model and to avoid the sensor deflection and shift in traditional sensor embedding method, as presented in Figure 3. It is necessary to pay attention to the waterproof of accelerometers. In this test, the plexiglass box was used to waterproof the accelerometers, as shown in Figure 3(a). It required 34 acquisition channels in total in this shaking table test.

2.5. Test Cases. Since the soft soil is impermeable, a few test cases can make the model foundation as close to the natural earthquake process as possible. The experiments were performed in horizontal excitation with a total of 11 test cases. Table 4 lists the test cases. Kobe (N-S) and EL-Centro $(\mathrm{N}-\mathrm{S})$ were selected for input acceleration and waveform, respectively, as presented in Figure 4. Earthquake details are listed in Table 5. Before the test, the soil model was previbrated with small amplitude white noise to make the soil denser. Besides, model soil was vibrated by inputting small amplitude white noise to monitor dynamic characteristics of the model system before the next test case. Each test case was carried after excess pore pressure dissipated. By inputting sine wave with the frequency close to natural frequency of 
TABLE 4: List of cases for experiment.

\begin{tabular}{|c|c|c|c|c|c|}
\hline No. & Test conditions code & Seismic wave name & Target acceleration/g & Time/s & Remarks \\
\hline 1 & $\mathrm{WN} 1$ & White noise & 0.1 & & \\
\hline 2 & SIN1 & Sine wave & 0.1 & 15 & $f=8 \mathrm{~Hz}$ \\
\hline 3 & $\mathrm{~K} 1$ & Kobe wave & 0.1 & 15 & $\Delta t=0.01 \mathrm{~s}$ \\
\hline 4 & EL1 & EL-Centro wave & 0.1 & 15 & $\Delta t=0.01 \mathrm{~s}$ \\
\hline 5 & WN2 & White noise & 0.1 & & \\
\hline 6 & K2 & Kobe wave & 0.2 & 15 & $\Delta t=0.01 \mathrm{~s}$ \\
\hline 7 & EL2 & EL-Centro wave & 0.2 & 15 & $\Delta t=0.01 \mathrm{~s}$ \\
\hline 8 & WN3 & White noise & 0.1 & & \\
\hline 9 & K3 & Kobe wave & 0.4 & 15 & $\Delta t=0.01 \mathrm{~s}$ \\
\hline 10 & EL3 & EL-Centro wave & 0.4 & 15 & $\Delta t=0.01 \mathrm{~s}$ \\
\hline 11 & WN4 & White noise & 0.1 & & \\
\hline
\end{tabular}

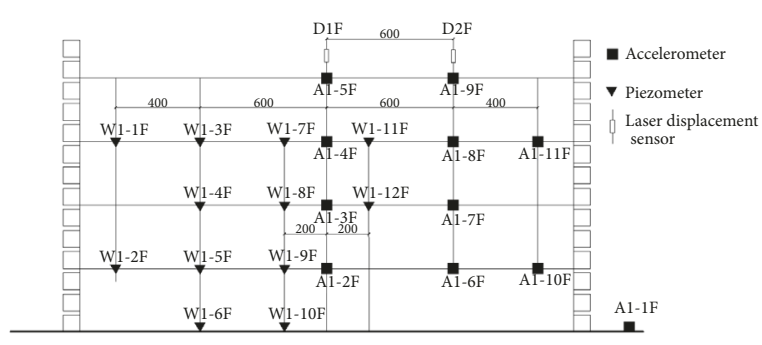

(a) The main observation section

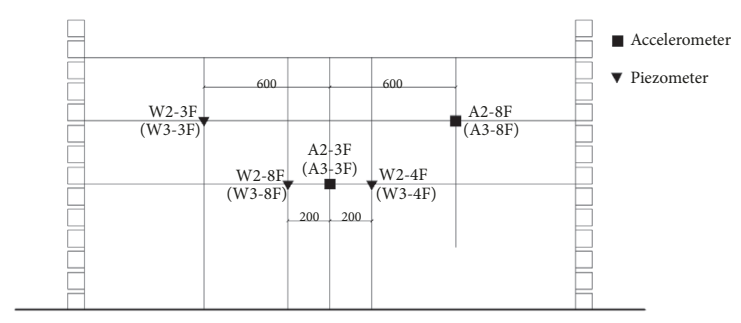

(b) Subobservation section

FIGURE 2: Layout of monitoring sensors of model test (unit: mm).

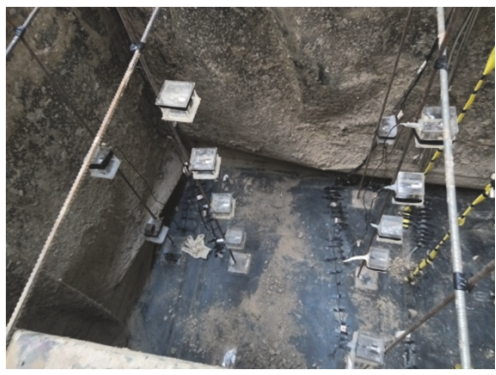

(a) Sensor layout of accelerometer

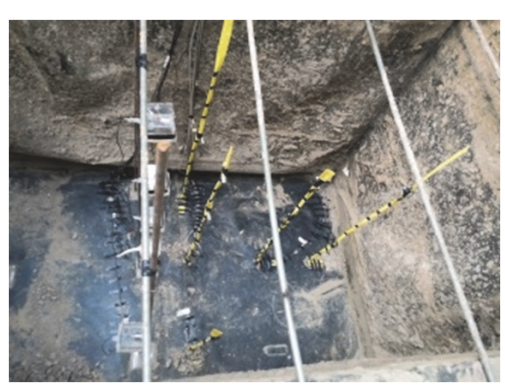

(b) Sensor layout of Piezometer

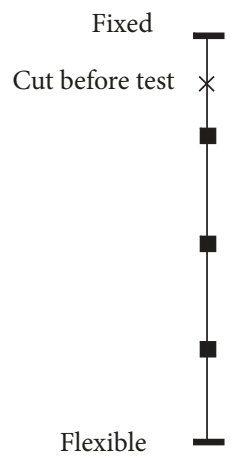

(c) Flexible chain sensors placement

FIGURE 3: Flexible chain sensors placement technology.

model system, the model system dynamic characteristics and boundary effect were monitored.

\section{Analysis of Test Results}

3.1. Model Box Performance and Boundary Effects. Figure 5 presents the time history comparisons of feature points' acceleration between model midline and boundary. Figure 6 presents the time history comparisons of feature points' dynamic pore pressure ratio between model midline and boundary. The seismic responses of measured points at the same depth are basically equal. The design of laminar shear model box is reasonable. Thus, the boundary effects can be ignored in this test.

3.2. Experimental Macroscopic Phenomena. The response of the soil surface after the corresponding shaking test is presented in Figure 7. The dynamic response of the model was slight under a small excitation, and a small amount of water overflows at the boundary of the box. As input ground motion increases progressively, the dynamic response of the model increases, and the settlement of the model surface also increases progressively. The amount of water on soil surface increases progressively too. The water surface overflows and 
TABLE 5: Earthquake record details.

\begin{tabular}{lcccccccc}
\hline Name & Arias Intensity $(\mathrm{m} / \mathrm{s})$ & Event & Year Station & Mag & Mechanism & Rjb $(\mathrm{km})$ & Rrup $(\mathrm{km})$ & Vs30(m/s) \\
\hline Kobe & 8.4 & Kobe, Japan & 1995 KJMA & 6.9 & Strike slip & 0.94 & 0.96 & 312 \\
\multirow{2}{*}{ EL-Centro } & \multirow{2}{*}{1.6} & Imperial & 1940 El Centro & 6.95 & Strike slip & 6.09 & 6.09 & 213 \\
\hline
\end{tabular}

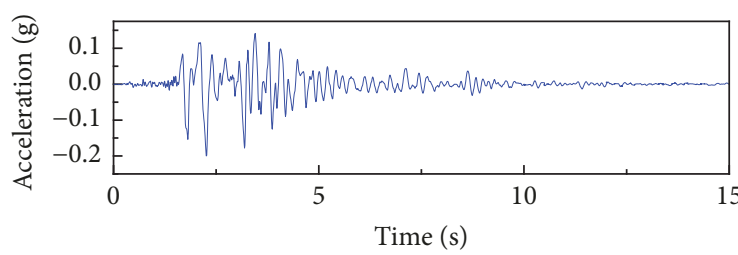

(a) Ground motion time history of Kobe waves

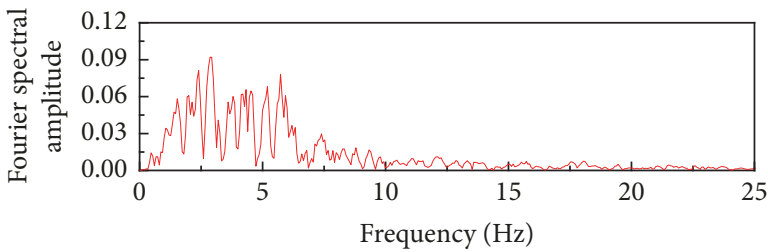

(c) Fourier spectral of Kobe wave

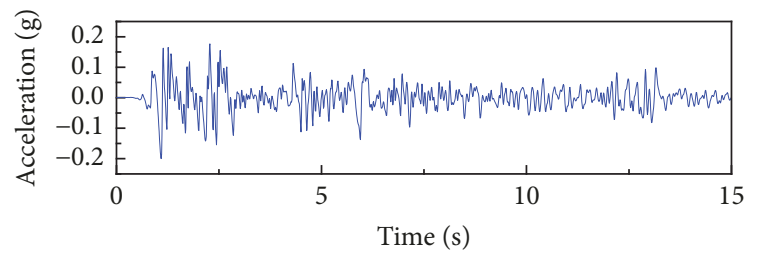

(b) Ground motion time history of EL-Centro waves

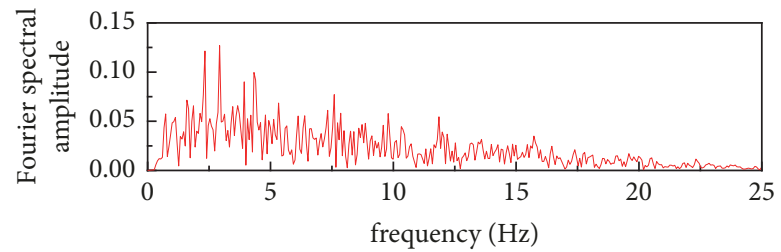

(d) Fourier spectrum of EL-Centro waves

FIGURE 4: Ground motion acceleration time histories and Fourier spectrum.

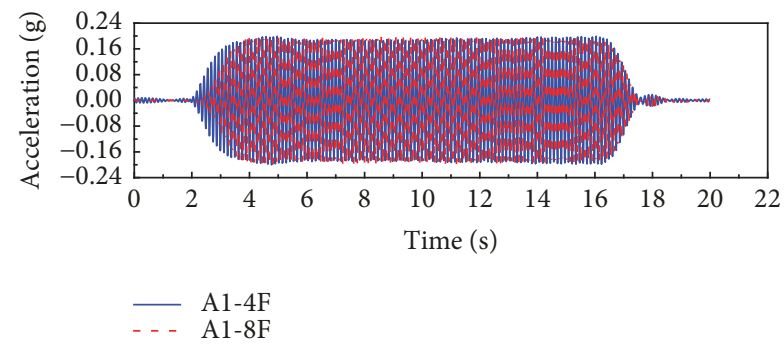

(a)

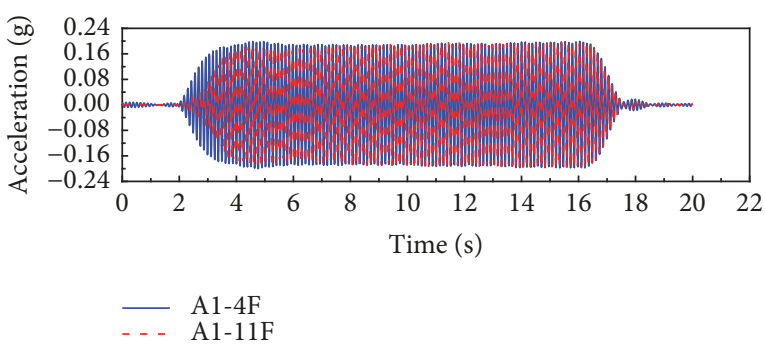

(c)

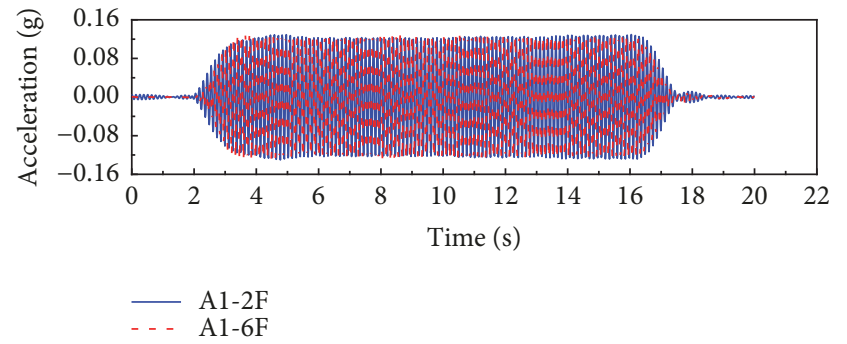

(b)

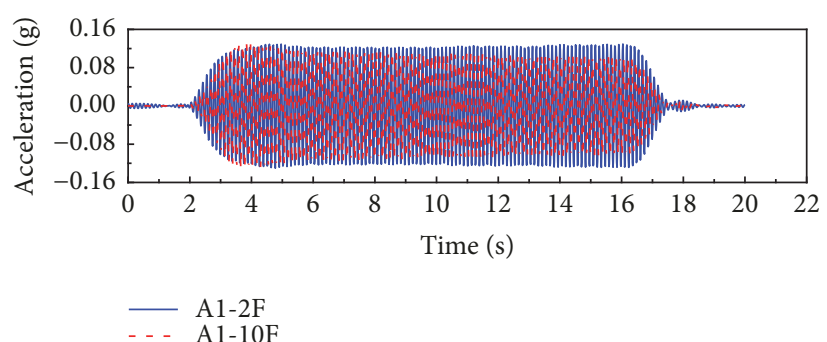

(d)

FIGURE 5: Time history comparisons of feature points' acceleration between model midline and boundary.

vibrates with a light wave-like movement. The depth of water layer is nearly $0.5 \mathrm{~cm}$ as all the cases of test were completed. Cumulative settlement displacement of model ground surface under different excitation levels is listed in Table 6. The settlement of model soil surface increases with the increase of the acceleration amplitude. The settlement of soil around the boundary is not significantly different from the surface center, showing similar seismic characteristics. The settlement of model surface center accumulates to $0.55 \mathrm{~cm}$ as all shaking table test cases were completed.

3.3. Dynamic Properties of Model System. Table 7 lists the characteristic frequency and damping ratios of model system. The initial characteristic frequency of model system reaches $8.85 \mathrm{~Hz}$, and the damping ratio reaches $3.6 \%$. As the input acceleration amplitude increases, the characteristic frequency 


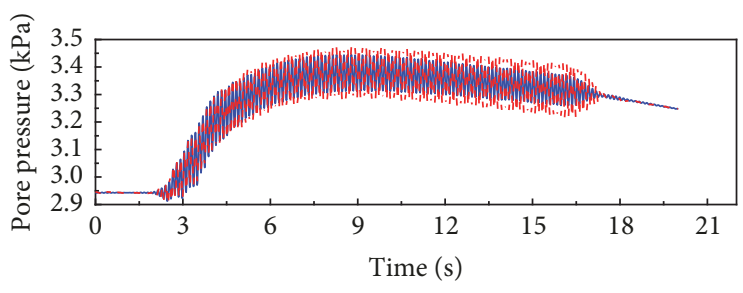

W $1-3 \mathrm{~F}$

- - W1-7F

(a)

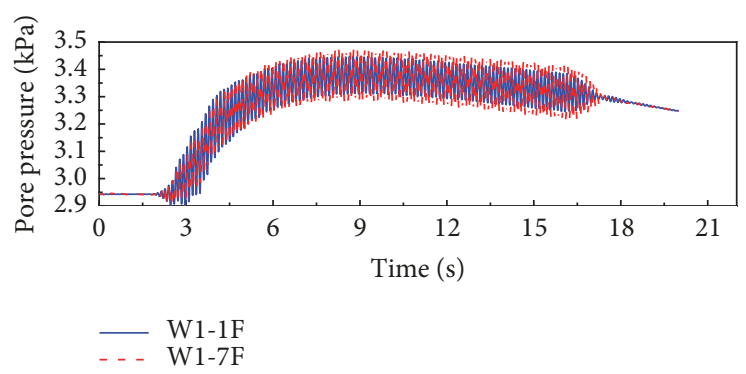

(c)

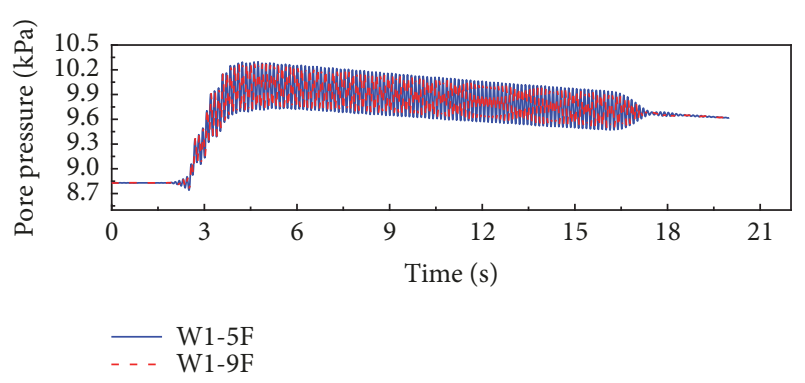

(b)

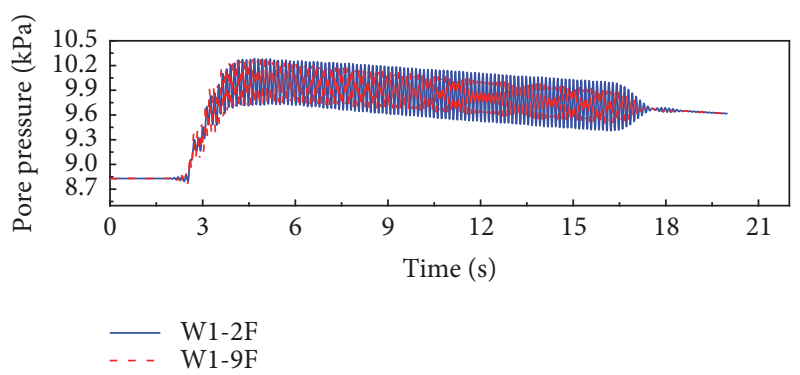

(d)

FIGURE 6: Time history comparisons of feature dynamic points' pore pressure ratio between model midline and boundary.

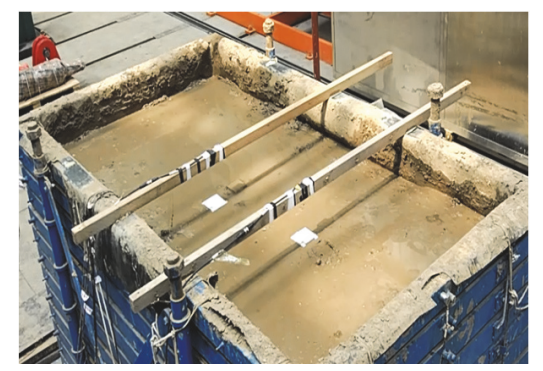

(a) $0.1 \mathrm{~g}$

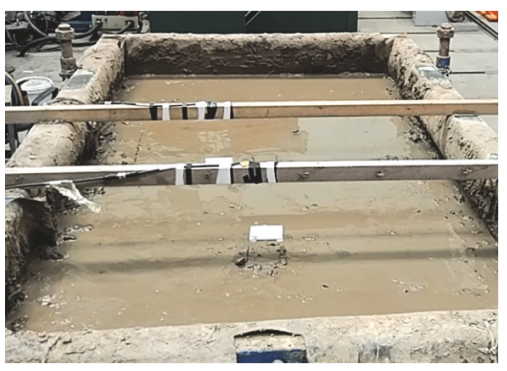

(b) $0.2 \mathrm{~g}$

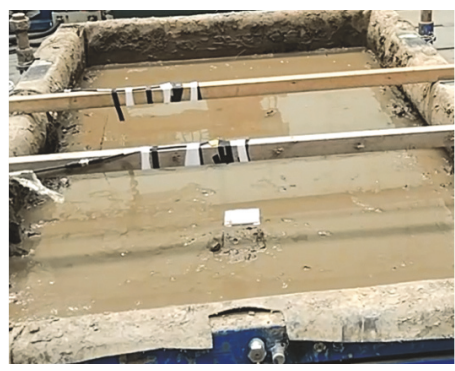

(c) $0.4 \mathrm{~g}$

FIGURE 7: Response of model test under different excitation conditions.

TABle 6: Cumulative settlement of soil surface under different excitation levels ( $\mathrm{mm})$.

\begin{tabular}{lll}
\hline Acceleration amplitude & $\mathrm{D}_{1 \mathrm{~F}}$ & $\mathrm{D}_{2 \mathrm{~F}}$ \\
\hline $0.1 \mathrm{~g}$ & 0.21 & 0.20 \\
$0.2 \mathrm{~g}$ & 0.32 & 0.32 \\
$0.4 \mathrm{~g}$ & 0.55 & 0.52 \\
\hline
\end{tabular}

of model system decreases, and the damping ratio increases progressively. The characteristic frequency decreases to $25 \%$ of the initial value, and the damping ratio is 1.8 times the initial damping ratio as the test cases have been completed.

In brief, the dynamic responses suggest that the characteristics frequency of model system decreases, and the damping ratio increases as input acceleration amplitude increases. This phenomenon is attributed to the rise of dynamic pore pressure, the decrease of dynamic shear strength, and dynamic shear modulus of soft soil.
3.4. Acceleration Responses. Acceleration amplification factor refers to the PGA (Peak Ground Acceleration) ratio of peak acceleration response at the measuring point to the peak input acceleration at the shaking table. Figure 8 presents the acceleration responses of midline measuring point under different shaking table test cases. The peak acceleration of Kobe decreases and then increases progressively when the acceleration propagates upward along the midline from the shaking table. The maximum PGA amplification factor of soils under small deformation conditions results from minor earthquakes input. Yet the PGA amplification coefficient at each measuring point along the soil depth decreases correspondingly with the increase of input acceleration amplitude. The same seismic characteristics are also presented by input EL-Centro waves, whereas the PGA amplification factor compared with input Kobe wave cases take on some differences. As this result suggests, the spectral components of the input seismic wave impact the acceleration to some extent. 
TABLE 7: Characteristic frequency and damping ratios of model system.

\begin{tabular}{lcc}
\hline Shaking table cases & Characteristic frequency/Hz & Damping ratio/\% \\
\hline WN1 & 8.85 & 3.6 \\
WN2 & 8.65 & 4.3 \\
WN3 & 8.16 & 5.7 \\
WN4 & 7.53 & 6.5 \\
\hline
\end{tabular}

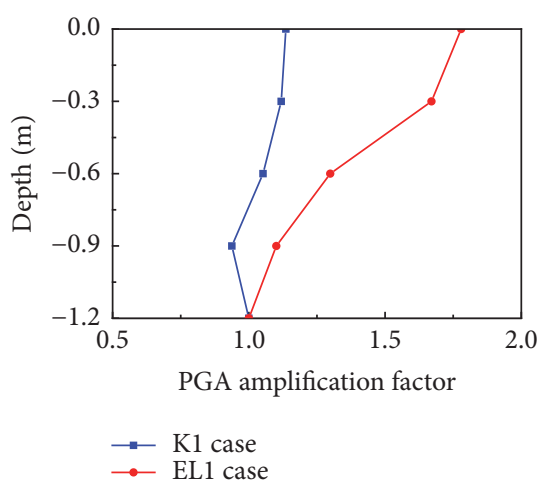

(a) $0.1 \mathrm{~g}$

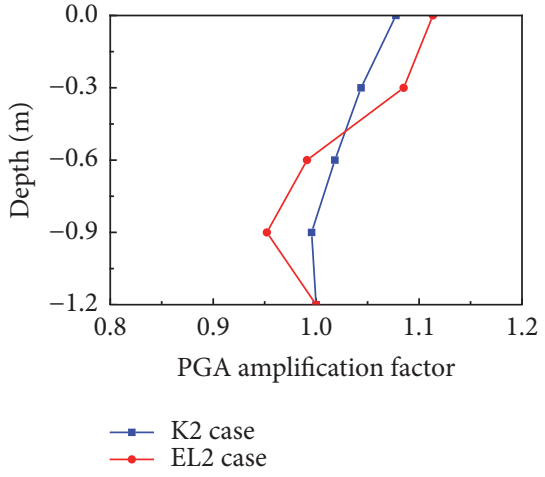

(b) $0.2 \mathrm{~g}$

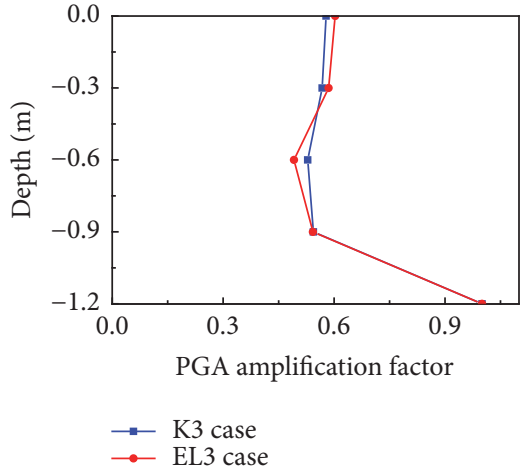

(c) $0.4 \mathrm{~g}$

FIGURE 8: Acceleration responses of midline measuring point under different shaking table test cases.

Figure 9 presents the acceleration response spectrum of measuring points under different excitation conditions, following the parabolic interpolation spectrum construction method. With the increase of input ground motion, the characteristic period of acceleration spectrum increases increasingly, agglomeration amplification effect of the short period weakens progressively, and agglomeration amplification effect of the long period increases progressively.

The amplification effect of the soil layer is associated with soil properties, earthquake intensity, as well as earthquake spectrum information. The saturated soft soil layer primarily plays an amplification role under the action of small or moderate earthquakes. The softening degree of the foundation progressively increases as the input acceleration amplitude increases. Under the energy consumption of soil, the high-frequency filtering and the low-frequency amplification effects increase evidently, and the model foundation shows the isolation and shock absorption. The effects of high-frequency filtering and long period amplification are presented in saturated soft soil.

3.5. Dynamic Pore Pressure Ratio Responses. According to the principle of effective stress, the dynamic pore pressure ratio is computed as the ratio of excess pore pressure to initial effective vertical stress. Figure 10 presents the peak value of pore pressure ratio along model midline under different excitation conditions.

The soft soil is impermeable as soft clay particles are finer, and bonding interactions are strong between the particles. Accordingly, pore pressure ratio is below 0.25 , which is at a low level. The peak pore pressure ratio of the saturated soft soil ground is located in the shallow buried soil layer, and, with the increase of the input ground motion intensity, the advantage of dynamic pore pressure ratio in this area is gradually weakened. At the identical input acceleration amplitude, Kobe waves, and EL waves are different in the pore pressure ratio. The pore pressure ratio and frequency information of acceleration are indicated to be associated. As the input acceleration amplitude increases, pore pressure ratio of corresponding measuring points increases, and the difference decreases progressively between shallow soils and deeper soils. It is difficult for the pore pressure dissipation as the saturated soil is impermeable. It is more significant effect to pore pressure ratio of the deeper soils under potent earthquake.

\section{Numerical Verification of Test Results}

4.1. Numerical Model. Saturated two-phase medium matrix numerical equation here is given as follows [18]:

$$
\begin{array}{r}
\boldsymbol{M} \ddot{\boldsymbol{u}}+\boldsymbol{C} \dot{\boldsymbol{u}}+\int_{\Omega} \boldsymbol{B}^{\mathrm{T}} \boldsymbol{\sigma}^{\prime} \mathrm{d} \Omega-\boldsymbol{Q} \boldsymbol{p}=\boldsymbol{f}^{\mathrm{u}} \\
\boldsymbol{Q}^{\mathrm{T}} \dot{\boldsymbol{u}}-\boldsymbol{S} \dot{\boldsymbol{p}}-\boldsymbol{H} \boldsymbol{p}=\boldsymbol{f}^{\mathrm{p}}
\end{array}
$$

where $\boldsymbol{M}$ denotes total mass matrix; $\boldsymbol{u}$ represents displacement vector; $\boldsymbol{B}$ refers to strain-displacement matrix, $\boldsymbol{B} \equiv$ $\boldsymbol{L} \boldsymbol{N}^{\boldsymbol{u}}$, which is associated with strain and displacement increments; $\boldsymbol{\sigma}^{\prime}$ denotes effective stress increments; $\boldsymbol{Q}$ represents soil-water coupled discrete gradient operators; $\boldsymbol{p}$ refers to pore pressure vector; $\boldsymbol{S}$ denotes compression coefficient matrix; $\boldsymbol{H}$ is permeability coefficient matrix; $\boldsymbol{f}^{\mathrm{u}}$ and $\boldsymbol{f}^{\mathrm{p}}$ represent soil-water mixture boundary conditions of body force and liquid phase boundary conditions of body force, respectively. 

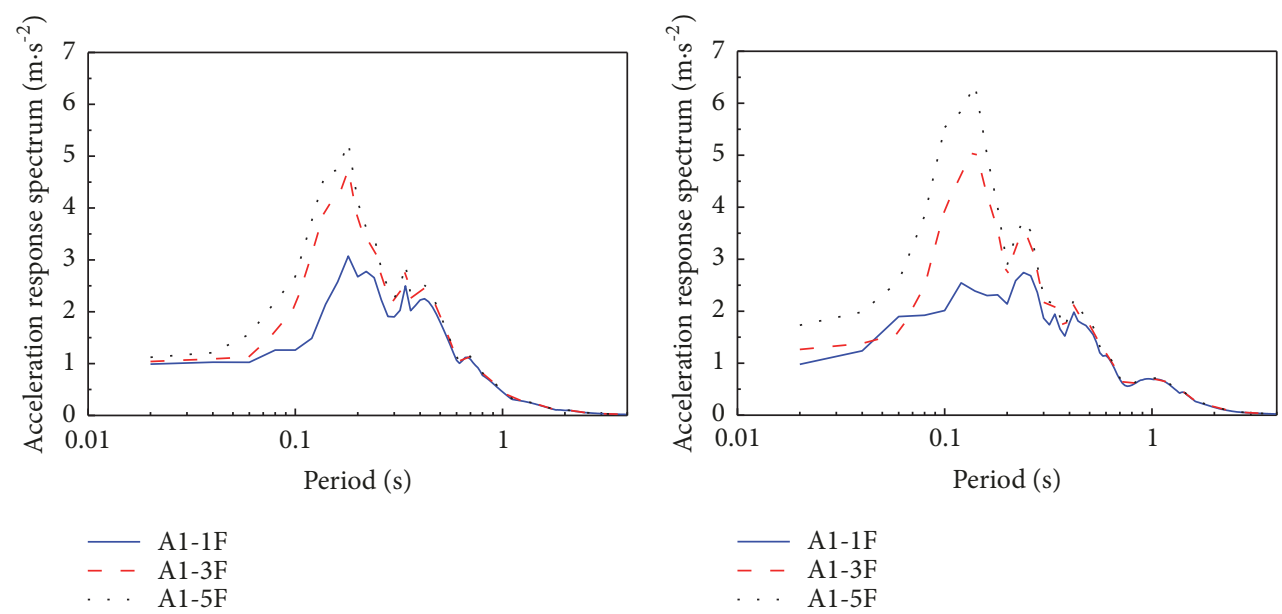

(a) K1 case

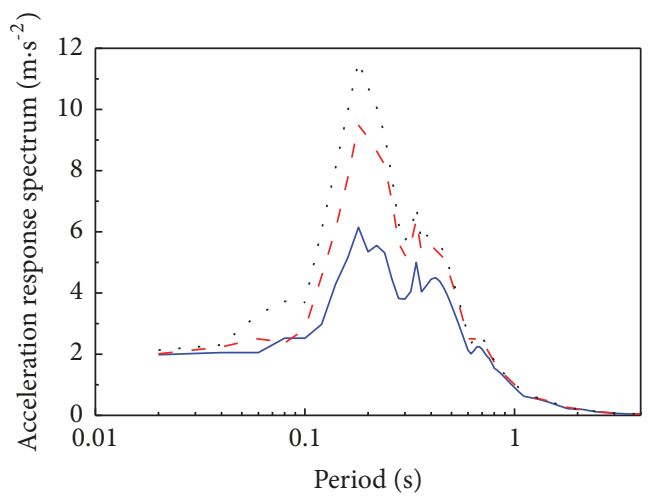

(b) EL1 case

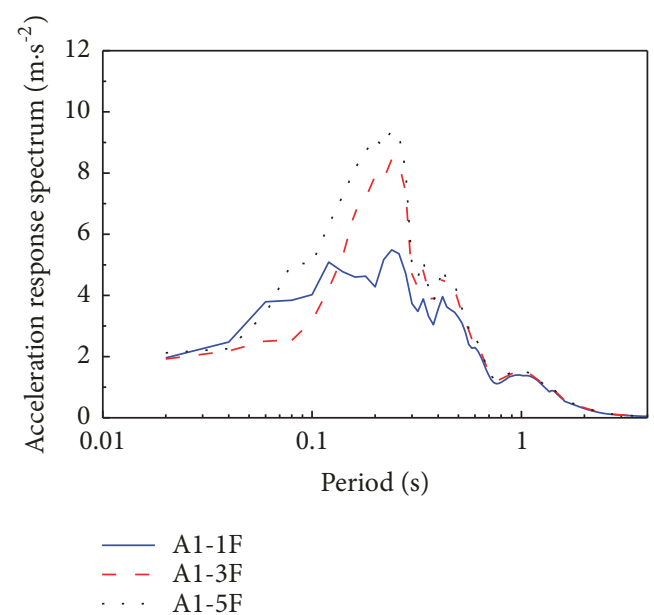

(c) $\mathrm{K} 2$ case

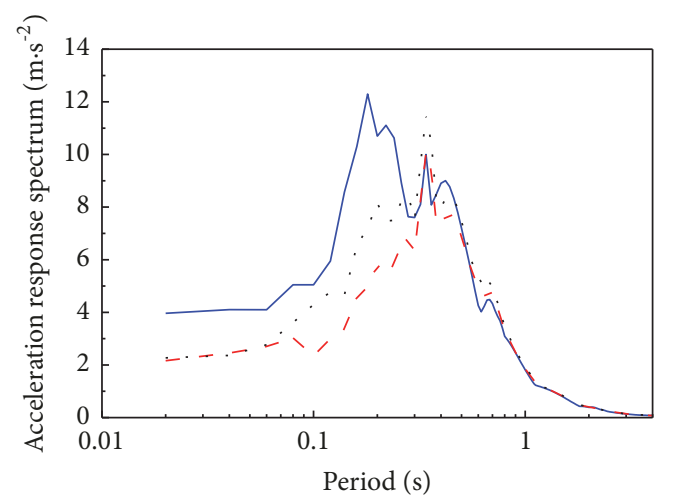

(d) EL2 case

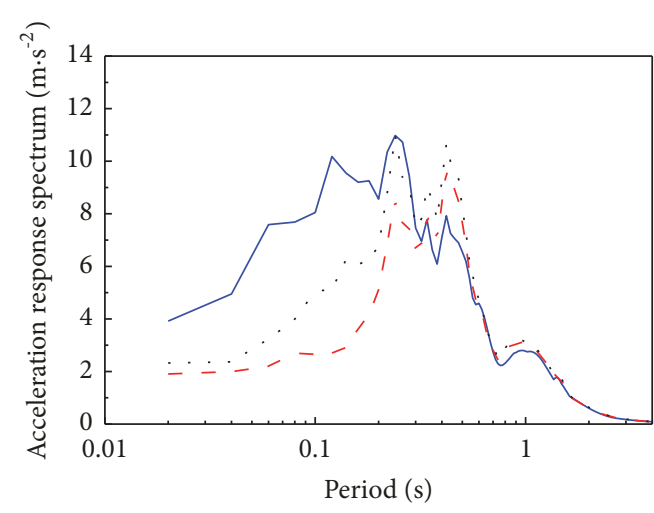

$$
\begin{array}{ll}
- & \mathrm{A} 1-1 \mathrm{~F} \\
-\ldots & \mathrm{A} 1-3 \mathrm{~F} \\
\cdots & \mathrm{A} 1-5 \mathrm{~F}
\end{array}
$$$$
\text { - A1-1F }
$$$$
-\quad \mathrm{A} 1-3 \mathrm{~F}
$$$$
\text { A1-5F }
$$

(e) K3 case

(f) EL3 case

FIGURE 9: Acceleration response spectrum of measuring points under different excitation conditions. 
TABLE 8: Model parameters of soft clay.

\begin{tabular}{lcccccccc}
\hline $\begin{array}{l}\text { Soil } \\
\text { parameter }\end{array}$ & $\rho\left(\mathrm{kg} \cdot \mathrm{m}^{-3}\right)$ & $G_{\text {ref }}(\mathrm{MPa})$ & $B_{\mathrm{ref}}(\mathrm{MPa})$ & $c(\mathrm{kPa})$ & $\gamma_{\max }$ & $\varphi$ & $n_{\mathrm{p}}$ & $k\left(\mathrm{~m} \cdot \mathrm{s}^{-1}\right)$ \\
\hline $\begin{array}{l}\text { Parameter } \\
\text { value }\end{array}$ & 1700 & 4.25 & 19.83 & 4.5 & 0.1 & 0 & 0 & $3 \times 10^{-7}$ \\
\hline
\end{tabular}

Note: $\rho$ is saturated soil mass density; $G_{\text {ref }}$ is reference low-strain shear modulus; $B_{\text {ref }}$ is reference bulk modulus; $c$ is apparent cohesion at zero effective confinement; $\gamma_{\max }$ is an octahedral shear strain at which the maximum shear strength is reached; $\varphi$ is friction angle at peak shear strength in degrees; $n_{\mathrm{p}}$ is an optional nonnegative constant defining variations of $G$ and $B$ as a function of initial effective confinement; $k$ is the permeability coefficient in horizontal and vertical directions; $n$ is the initial porosity.

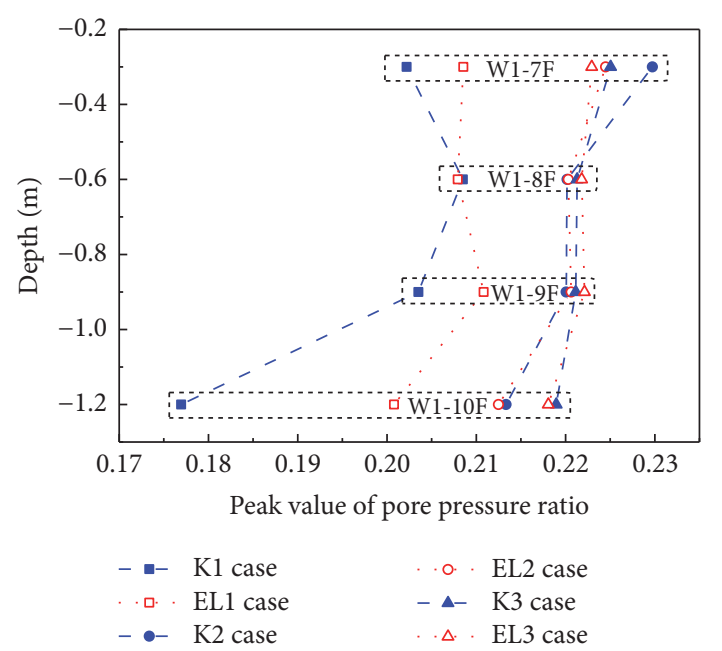

FIGURE 10: Peak dynamic pore pressure ratio of measuring points under different excitation conditions.

Multiyield surface motion plastic constitutive was applied for soft clay, and multiyield surface model equation is expressed in the following:

$$
\begin{array}{r}
\boldsymbol{f}_{\boldsymbol{m}}=\left\{\frac{3}{2}\left(\boldsymbol{\tau}-\boldsymbol{\alpha}^{(\boldsymbol{m})}\right):\left(\boldsymbol{\tau}-\boldsymbol{\alpha}^{(\boldsymbol{m})}\right)\right\}^{1 / 2}-\boldsymbol{K}^{(\boldsymbol{m})}=0 \\
(\boldsymbol{m}=1,2, \ldots, \boldsymbol{n})
\end{array}
$$

where $\boldsymbol{\tau}$ denotes deviatoric stress tensor; $m$ represents the $m_{\text {th }}$ yield surface numbered, $m \in(1,2, \ldots, n) ; n$ refers to the total number of yield surfaces; $\boldsymbol{\alpha}^{(\boldsymbol{m})}$ and $\boldsymbol{K}$ represent the center and radius of the $m_{\text {th }}$ yield surface, respectively; and $\boldsymbol{K}^{(\boldsymbol{m})}$ denotes the cube root of two times that of yield surface radius. $\boldsymbol{A}: \boldsymbol{B}=\boldsymbol{A}_{i j}: \boldsymbol{B}_{i j}$.

PressureIndependMultiYield material counts as an elastic-plastic material where plasticity merely presents in the deviatoric stress-strain response. The volumetric stress-strain response is linear-elastic and independent of the deviatoric response. This material is introduced to simulate monotonic or cyclic response of materials, and these shear behaviors are insensitive to the confinement variation.

Yield surface motion direction tensor is expressed in the following:

$$
\boldsymbol{\mu}=\left[\boldsymbol{s}_{\mathrm{T}}-\boldsymbol{\alpha}^{\boldsymbol{m}}\right]-\frac{\boldsymbol{M}_{\boldsymbol{m}}}{\boldsymbol{M}_{\boldsymbol{m}+1}}\left[\boldsymbol{s}_{\mathrm{T}}-\boldsymbol{\alpha}^{\boldsymbol{m}+1}\right]
$$

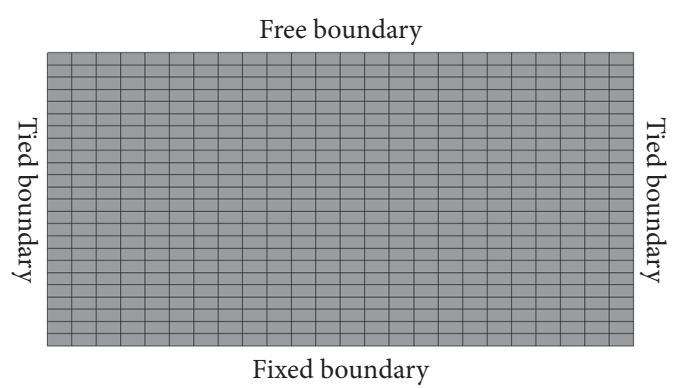

FIGURE 11: Model grid of finite element method.

where $\boldsymbol{s}_{\mathrm{T}}$ denotes the second-order deviatoric stress tensor, the deviatoric stress tensor at the intersection of the yield surface $f_{m+1}$ and $f_{m} ; \boldsymbol{\alpha}_{\boldsymbol{m}}$ and $\left(\boldsymbol{p}^{\prime}+\boldsymbol{p}_{0}^{\prime}\right) \boldsymbol{\alpha}_{\boldsymbol{m}+1}$ represent yield surface center of $f_{m+1}$ and $f_{m}$, respectively.

The site soil is simulated using 4-noded quadUP elements. These elements have three degrees of freedom per node: two for displacements and one for pore pressure. These elements can be used to model coupled pore pressure displacement analysis following the $u$ - $p$ formulation. In this model, the continuum material models, referred to as nDMaterial, are used to simulate the mechanical behavior of clay, and they are attached to continuum elements. The soft soil constitutive calculation parameters are listed in Table 8 [19] (Mckenna, 2009).

Figure 11 presents the model grid of finite element method. The bottom of the model is fixed in such a way that no movement is allowed on the vertical and horizontal direction. The pore pressure is allowed to fluctuate freely, which means that there is no drainage on the bottom. The pore does not allow to fluctuate freely in surface, which means that there is drainage on the model surface. The displacements of the model on the sides at the level of clay are periodic conditions: each side has the same displacement with the other side. That is, both sides of the model are set as the tied boundary. In the OpenSEES program, the behavior of the laminar box can be modeled by adopting tied node feature. This feature allows the horizontal and vertical displacement at the two boundaries with the identical value. The stress-strain behavior of the material model for saturated soil could simulate the hysteresis damping to a certain extent.

The viscous effect of the pore fluid also incorporates damping. Yet the plastic hysteresis would not be able to capture the full damping of the soils in the low strain range. The soil is very large in damping at a small confining pressure, 
which is difficult to simulate by adopting the stress-strain relationship. Thus, a 5\% viscous damping of Raleigh type was involved in the dynamic analysis for the soft soil [20]. HilberHughes-Taylor method was used for time integration algorithms in soil dynamics. It is an implicit method considering energy dissipation and second-order accuracy (which is not possible following the regular Newmark method), and this method can be unconditionally stable in terms of the choices of input parameters.

The actual input acceleration and the target acceleration are different in the shaking table test. Thus, the output acceleration of the shaking table is selected as the ground motion input for numerical simulation. Turn on the gravity and solve problems in the static case to use elastic material for the entire model. It is performed by solving a coupled transient analysis with time-steps. The large time-steps $(\mathrm{dt}=5$ $\times 10^{5} \mathrm{~s}$ ) are employed to ensure analysis to be drained, and any initial excess pore pressures have been dissipated. After the elastic steps, the material is switched to an elastoplastic state, and a similar large time-step is performed when all the initial transients and excess pore pressures have been dissipated. After the elastoplastic gravity step, the analysis object is destroyed, and the time is reset to zero. The dynamic analysis is then executed. The test to judge when convergence has been achieved is based on increments of energy. This is a good criterion in an elastoplastic problem where increments of displacement can be really large during yielding. The constraint handler is set as the transformation handler, after recommendations from the creators of the quadUP elements when one is applying pore pressure boundary conditions. The algorithm selected is a KrylovNewton algorithm. It is a robust and simple algorithm with asymptotically quadratic rate of convergence. The system used is a ProfileSPD. The Jacobian matrix of frictional materials is not symmetric but in many situations ignoring the nonsymmetric elements can help improve performance without significant differences in the results. All numerical calculation results are extracted and visualized using the interface program of GID with MATLAB.

4.2. Numerical Verification. The numerical verification is mostly based on the peak comparison of the dynamic response index or only the qualitative comparison of the time history response. For the aim to the quantitative evaluation of the accuracy of the numerical simulation results, the root mean square error (RMSE) is used to measure the difference between the shaking table test and the numerical calculation results, and the consistency analysis between them is also carried out.

The root mean square error is defined as follows:

$$
R M S E=\sqrt{\frac{1}{n} \sum_{i=1}^{n}\left(\hat{x}_{i}-x_{i}\right)^{2}}
$$

where $\widehat{x}_{i}$ is the results of numerical simulation; $x_{i}$ is the results of test.

In particular, the root mean square error is only reliability estimate of a set of measured data, rather than the actual error
TABLE 9: Comparison of surface subsidence between experimental results and numerical simulation $(\mathrm{mm})$.

\begin{tabular}{lcc}
\hline Test cases & Test results & Numerical results \\
\hline K2 & 0.318 & 0.209 \\
EL2 & 0.319 & 0.211 \\
\hline
\end{tabular}

of the two or the error range. It reflects the extent to which the dynamic response results of numerical simulation deviates from the test results. According to the Gaussian theory of random error, when the root mean square error of measured values is $\sigma$, then the random error $\varepsilon$ has a probability of $68.3 \%$ in $(-\sigma, \sigma)$. The smaller the RSME value, the lower the error and the better the consistency, which means that the numerical simulation accuracy is higher.

Table 9 lists the acquired subsidence of both experimental results and numerical simulation. Ground surface settlement of test is nearly $30 \%$ greater than that in numerical method, because PressureIndependMultiYield material is an elasticplastic material in which plasticity exhibits only the deviatoric stress-strain response, and the volumetric stress-strain is linear-elastic and is independent of the deviatoric response. This material is implemented to simulate monotonic or cyclic response of materials whose shear behavior is insensitive to the confinement change, which is attributed to the shaking additive effect.

Thus, the experimental cumulative settlement and corresponding numerical simulation results are not very well consistent with each other to some extent.

Figure 12 presents the time history comparison of acceleration response between shaking table test and corresponding numerical simulation results. Figure 13 presents the comparison of acceleration response at feature points between shaking table test and corresponding numerical simulation results. As illustrated in Figures 12 and 13, the RMSE of acceleration time history is $0.2879 \mathrm{~m} \cdot \mathrm{s}^{-2}$ and $0.3721 \mathrm{~m} \cdot \mathrm{s}^{-2}$ for $\mathrm{W} 1-3 \mathrm{~F}$ and $\mathrm{W} 1-5 \mathrm{~F}$, respectively, in $\mathrm{K} 2$ case, and the RMSE of acceleration time history is $0.4074 \mathrm{~m} \cdot \mathrm{s}^{-2}$ and $0.5468 \mathrm{~m} \cdot \mathrm{s}^{-2}$ for W1-3F and W1-5F, respectively, in EL2 case, while the RMSE of acceleration response spectrum is $0.1000 \mathrm{~m} \cdot \mathrm{s}^{-2}$ and $0.1301 \mathrm{~m} \cdot \mathrm{s}^{-2}$ for $\mathrm{W} 1-3 \mathrm{~F}$ and $\mathrm{W} 1-5 \mathrm{~F}$, respectively, and the RMSE of acceleration response spectrum is $0.1507 \mathrm{~m} \cdot \mathrm{s}^{-2}$ and $0.1032 \mathrm{~m} \cdot \mathrm{s}^{-2}$ for $\mathrm{W} 1-3 \mathrm{~F}$ and $\mathrm{W} 1-5 \mathrm{~F}$, respectively. Both the experimental results and the numerical simulation results are well consistent with $\mathrm{K} 2$ case regardless of the time history or the Fourier spectrum of acceleration responses, while it is not consistency for low period in EL2 case; specifically, the predominant period $(0.14 \mathrm{~s})$ of measuring point acceleration is greater than that in the test result $(0.24 \mathrm{~Hz})$ in EL2 case. The shape of both errors has better consistency though both errors are confined in $40 \%$. The consistency of acceleration response between numerical results and test results is also associated with the spectrum characteristics of input ground motions.

Figure 14 presents the time history comparison of pore pressure ratio between the shaking table test and numerical results. The numerical results of time history of pore pressure ratio are well consistent with the test results under different excitation conditions. Negative pore pressure phenomenon 


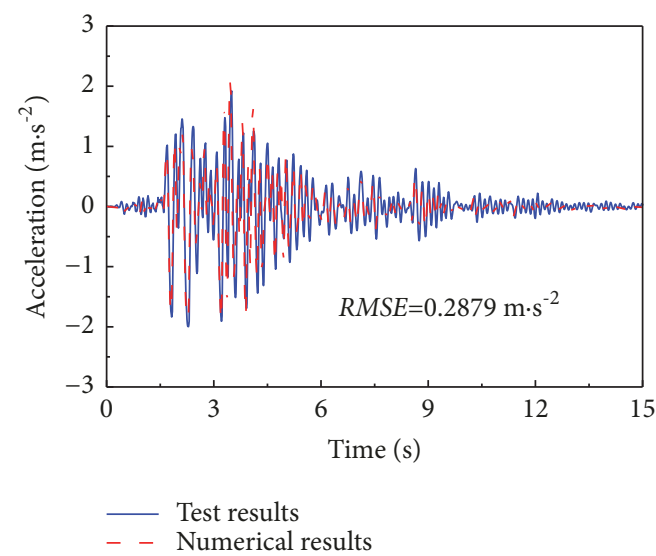

(a) A1-3F (K2 case)

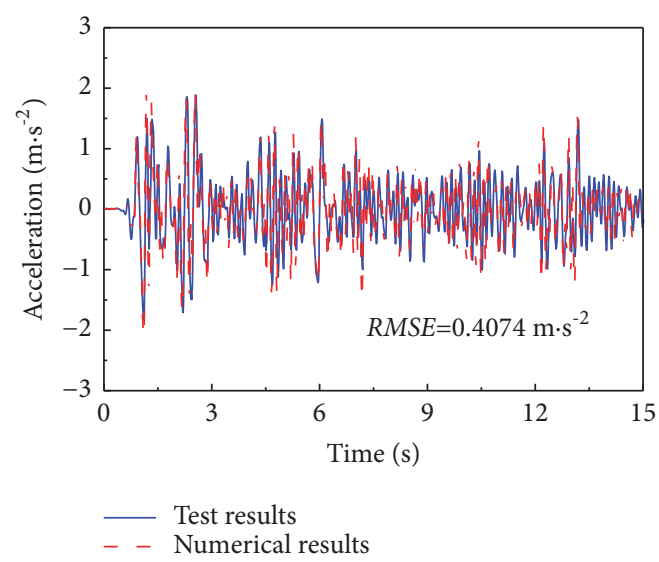

(c) A1-3F (EL2 case)

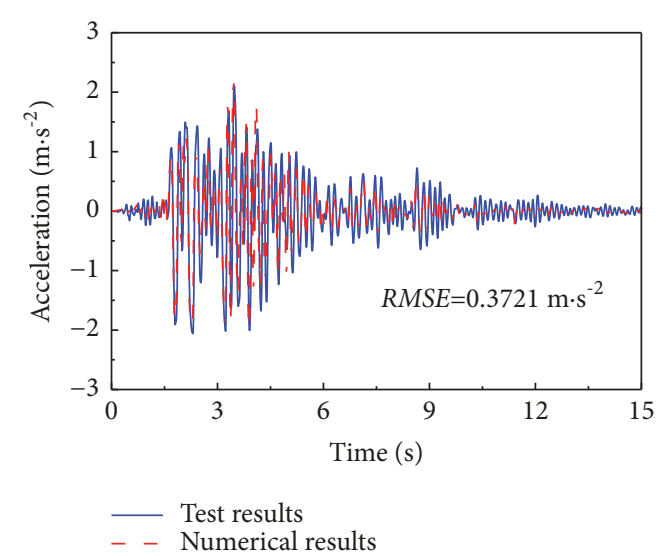

(b) $\mathrm{A} 1-5 \mathrm{~F}$ (K2 case)

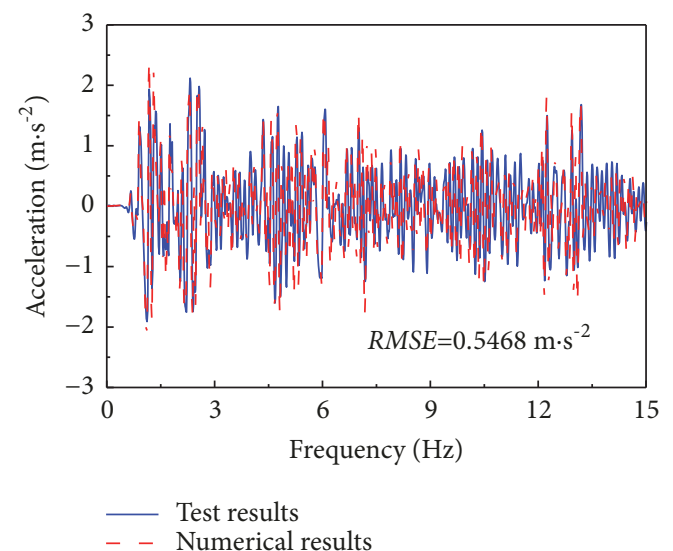

(d) A1-5F (EL2 case)

FIGURE 12: The time history comparison of acceleration response between shaking table test and corresponding numerical simulation results.

occurs around piezometer resulting from dilatancy of soft soil under input ground motion.

Figure 15 presents the peak response contours of pore pressure ratio under different excitation conditions. The peak value of pore pressure ratio in shallow soil is greater than that in the deeper soil, and these results are consistent with those of the literature [21] (Gao, 2011). The RMSE of pore pressure ratio is 0.0290 and 0.0238 for W1-7F and W1-9F, respectively, in $\mathrm{K} 2$ case, and the $R M S E$ of pore pressure ratio is 0.0324 and 0.0294 for W1-7F and W1-9F, respectively, in EL2 case. The peak response contours of pore pressure ratio of free field in soft soil are associated with the frequency spectrum characteristics of the input ground motion, whereas the variation results of them are similar.

The comparison is presented merely between the shaking table test and the numerical simulation under the $0.2 \mathrm{~g}$ ground motion. Also, the test results of other shaking table test case and corresponding numerical simulation results are found with good consistency. It is noteworthy that soft soil is homogenous in model test, whereas the soil of project site is sophisticated in geological conditions with heterogeneous, inclined, or underground structure embedded. Thus, it is easy to flow for soft soil and damage of the underground structure because of the uneven deformation resulting from soil softening.

\section{Conclusions}

The regularity of the macroscopic phenomena of test, the dynamic characteristics of the model system, the acceleration responses, and the dynamic pore pressure (ratio) responses are analyzed in this paper from the shaking table test results of the saturated soft soil free field. Also, the comparison between the test results and the numerical simulation results is anatomized. The reliability of the numerical simulation method is analyzed by the quantitative evaluation of the root mean square error. The results are presented in the following.

(1) The characteristic frequency of the model system decreases progressively, whereas damping ratio increases increasingly with the increase of ground motion acceleration and the number of vibrations. The initial characteristic frequency and damping ratio are quite different compared with the end of the shaking table test.

(2) The seismic wave propagates in the model ground and the acceleration response spectrum amplitude of the short period components decreases while the acceleration 


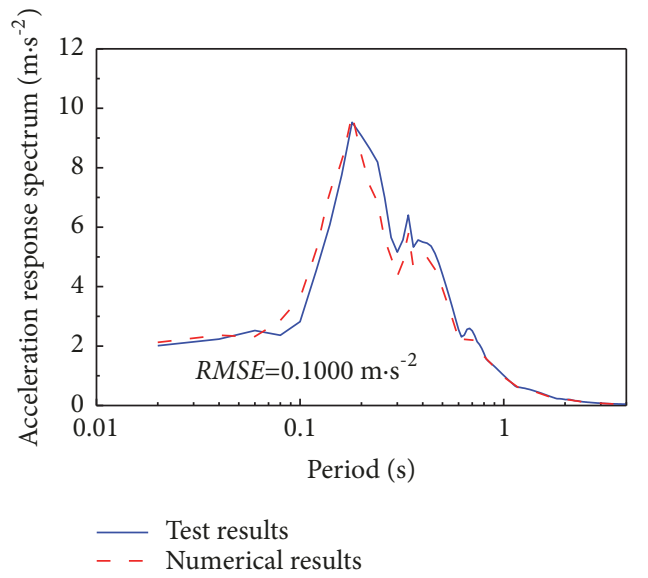

(a) $\mathrm{Al}-3 \mathrm{~F}$ (K2 case)

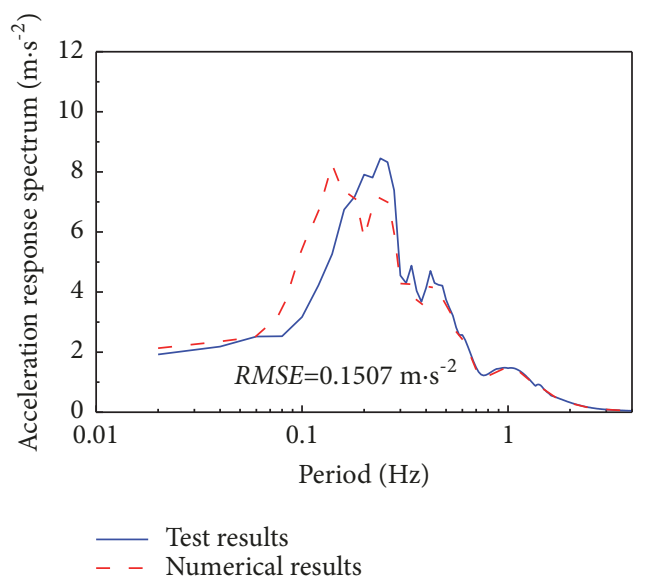

(c) A1-3F (EL2 case)

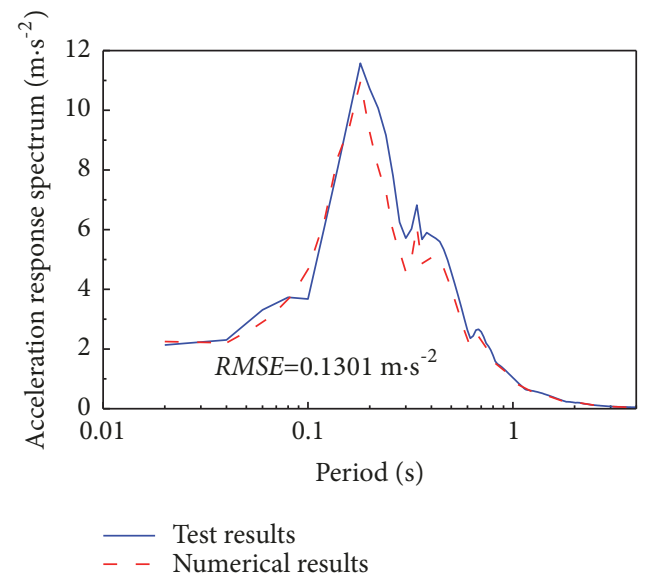

(b) A1-5F (K2 case)

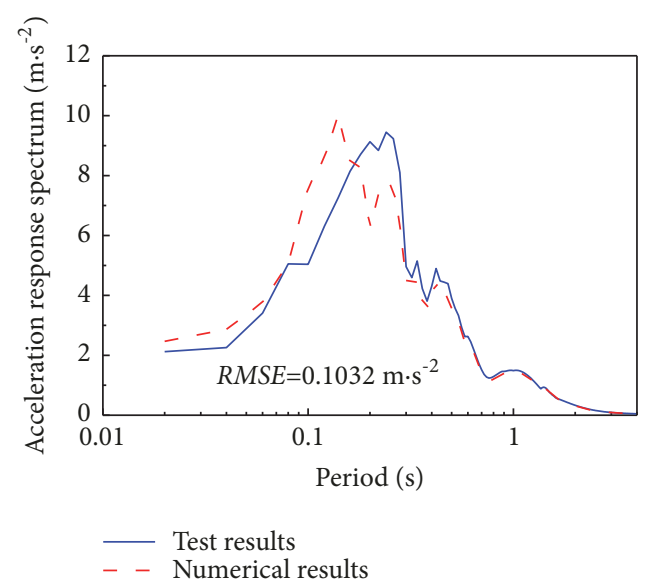

(d) A1-5F (EL2 case)

FIGURE 13: Comparison of acceleration response spectrum at feature points between the test and corresponding numerical simulation results.

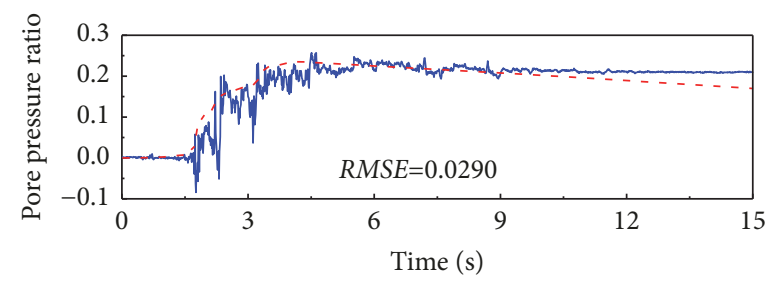

_ Test results

_. - Numerical results
(a) $\mathrm{W} 1-7 \mathrm{~F}(\mathrm{~K} 2$ case $)$

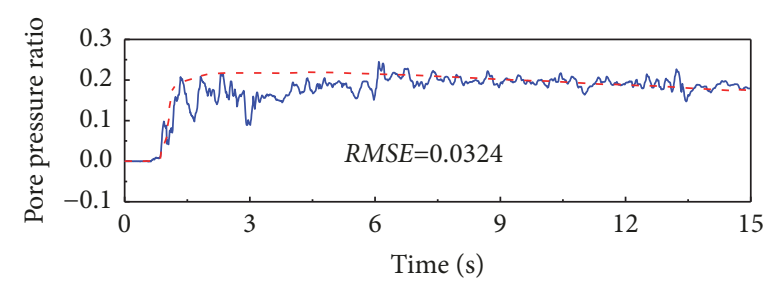

Test results

- - Numerical results

(c) W1-7F(EL2 case)

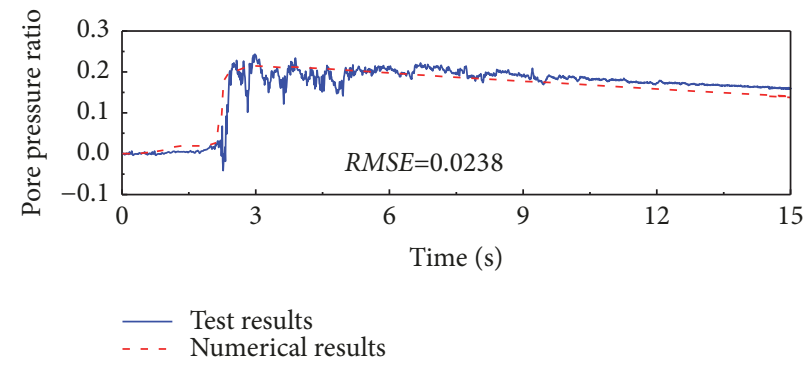

(b) W1-9F(K2 case)

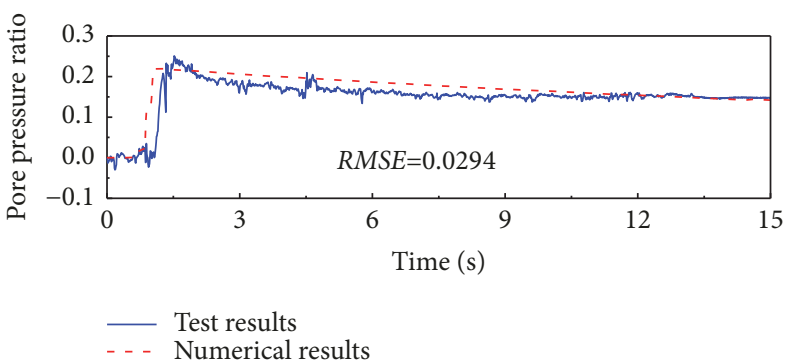

(d) $\mathrm{W} 1-9 \mathrm{~F}(\mathrm{EL} 2$ case $)$

FIGURE 14: Time series comparison of pore pressure ratio between the shaking table test and numerical results. 


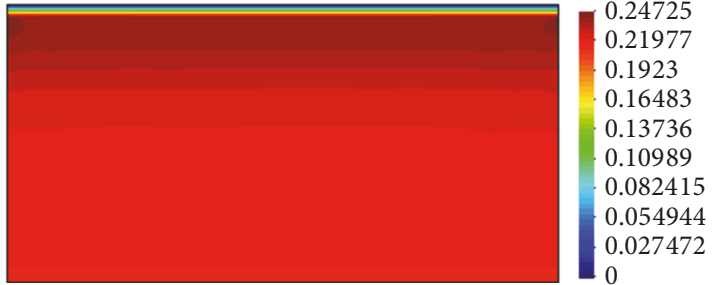

(a) K2 case

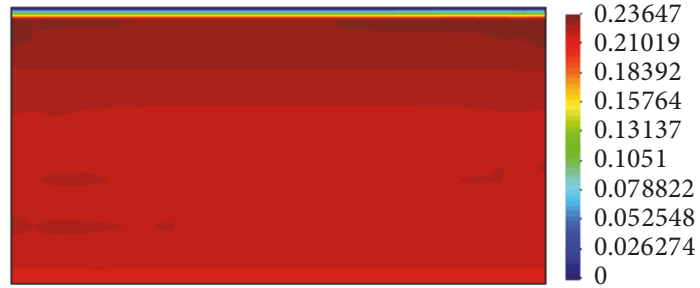

(b) EL2 case

FIGURE 15: The peak response contours of pore pressure ratio under different excitation conditions.

response spectrum amplitude of the long period components increases from the bottom to the top of the ground. The PGA amplification factor is amplified along the soil layer to the surface under small or moderate ground motions. The failure of the foundation model takes on the isolation and shock absorption under strong ground motions.

(3) The peak value of pore pressure ratio is at a low level in saturated soft ground. The peak pore pressure ratio of the saturated soft soil ground is located in the shallow buried soil layer, and, with the increase of the input ground motion intensity, the advantage of dynamic pore pressure ratio in this area is gradually weakened. It is more significant effect to pore pressure ratio of the deeper soils under potent earthquake.

(4) The full coupled effective stress numerical simulation method and the shaking table model test results are in good agreement with each other regardless of displacement, acceleration, and pore pressure. This also suggests that it is reliable to further build other more sophisticated prototype site conditions.

\section{Data Availability}

The data used to support the findings of this study are available from the corresponding author upon request.

\section{Conflicts of Interest}

The authors declare that there are no conflicts of interest regarding the publication of this paper.

\section{Acknowledgments}

This research was supported by the National Natural Science Foundation of China (Grant 51578100) and the Funding on Fundamental Research in Central Universities (Grants 3132014326 and 3132017022).

\section{References}

[1] K. Kawashima, "Seismic design of underground structures in soft ground-a review," in Geotechnical Aspects of Underground Construction in Soft Ground, O. Kusakabe, K. Fujita, and Y. Miyazaki, Eds., Balkema, Rotterdam, 1999.

[2] Y. M. A. Hashash, J. J. Hook, and B. Schmidt, "Seismic design and analysis of underground structures," Tunnelling \& Underground Space Technology, vol. 16, no. 4, pp. 247-293, 2001.
[3] K. Yamashita, J. Hamada, S. Onimaru, and M. Higashino, "Seismic behavior of piled raft with ground improvement supporting a base-isolated building on soft ground in Tokyo," Soils and Foundations, vol. 52, no. 5, pp. 1000-1015, 2012.

[4] A. Turan, Physical Modelling of Seismic Soil-Structure Interaction of Embedded Structures [Ph.D. thesis.], the University of Western Ontario, London, UK, 2009.

[5] J. Chen, X. Shi, and J. Li, "Shaking table test of utility tunnel under non-uniform earthquake wave excitation," Soil Dynamics and Earthquake Engineering, vol. 30, no. 11, pp. 1400-1416, 2010.

[6] J. Chen, L. Jiang, J. Li, and X. Shi, "Numerical simulation of shaking table test on utility tunnel under non-uniform earthquake excitation," Tunnelling and Underground Space Technology, vol. 30, pp. 205-216, 2012.

[7] C. Guoxing, C. Su, Z. Xi, D. Xiuli, Q. I. Chengzhi, and W. Zhihua, "Shaking-table tests and numerical simulations on a subway structure in soft soil," Soil Dynamics and Earthquake Engineering, vol. 76, pp. 13-28, 2015.

[8] Z. Chen, W. Chen, Y. Li, and Y. Yuan, "Shaking table test of a multi-story subway station under pulse-like ground motions," Soil Dynamics and Earthquake Engineering, vol. 82, pp. 111-122, 2016.

[9] H.-F. Wang, M.-L. Lou, X. Chen, and Y.-M. Zhai, "Structuresoil-structure interaction between underground structure and ground structure," Soil Dynamics and Earthquake Engineering, vol. 54, pp. 31-38, 2013.

[10] Z. Haiyang, H. Zhonghua, and C. Guoxing, "Numerical modeling on the seismic responses of a large underground structure in soft ground," Journal of Vibroengineering, vol. 17, no. 2, pp. 802-815, 2015.

[11] J. Huang, M. Zhao, and X. Du, "Non-linear seismic responses of tunnels within normal fault ground under obliquely incident $\mathrm{P}$ waves," Tunnelling and Underground Space Technology, vol. 61, pp. 26-39, 2017.

[12] Q. S. Chen, G. Y. Gao, and J. Yang, "Dynamic response of deep soft soil deposits under multidirectional earthquake loading," Engineering Geology, vol. 121, no. 1-2, pp. 55-65, 2011.

[13] J. Zhou, P. Dong, and Y. Chi, "Research on seismic soil pressure of underground structures in soft soils," Yantu Lixue/Rock and Soil Mechanics, vol. 25, no. 4, pp. 554-559, 2004.

[14] M. Azadi and S. M. Mir Mohammad Hosseini, "Analyses of the effect of seismic behavior of shallow tunnels in liquefiable grounds," Tunnelling and Underground Space Technology, vol. 25, no. 5, pp. 543-552, 2010.

[15] B. A. Schrefler and R. Scotta, "A fully coupled dynamic model for two-phase fluid flow in deformable porous media," Computer Methods Applied Mechanics and Engineering, vol. 190, no. 24-25, pp. 3223-3246, 2001. 
[16] L. Maotian, Z. Xiaoling, Y. Qing, and G. Ying, "Numerical analysis of liquefaction of porous seabed around pipeline fixed in space under seismic loading," Soil Dynamics and Earthquake Engineering, vol. 29, no. 5, pp. 855-864, 2009.

[17] A. Ghassemi, A. Pak, and H. Shahir, "Numerical study of the coupled hydro-mechanical effects in dynamic compaction of saturated granular soils," Computers \& Geosciences, vol. 37, no. 1-2, pp. 10-24, 2010.

[18] A. C. Chan and A. Elgamal, "Nonlinear modeling of largescale ground-foundation-structure seismic response," Journal of Earthquake Technology, vol. 44, no. 2, pp. 325-339, 2007.

[19] F. Mckenna, S. Mazzoni, and M. H. Scott, Opensees system for earthquake engineering simulation user command-language manual, Pacific Earthquake Engineering Research Center, University of California, Berkeley, 2009.

[20] H. Liu and E. Song, "Seismic response of large underground structures in liquefiable soils subjected to horizontal and vertical earthquake excitations," Computers \& Geosciences, vol. 32, no. 4, pp. 223-244, 2005.

[21] G.-Y. Gao, Q.-S. Chen, J.-F. He, and X.-L. Zhang, "Effect of rise of groundwater table on seismic ground response of soft soil in Shanghai," Yantu Gongcheng Xuebao/Chinese Journal of Geotechnical Engineering, vol. 33, no. 7, pp. 989-995, 2011. 


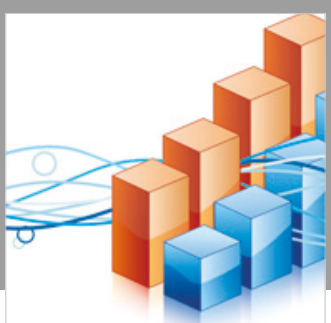

Advances in

Operations Research

\section{-n-m}
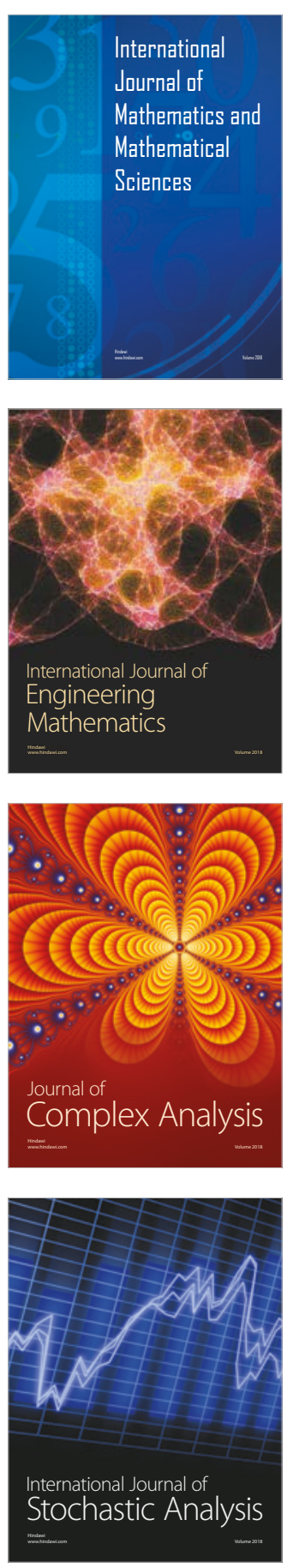
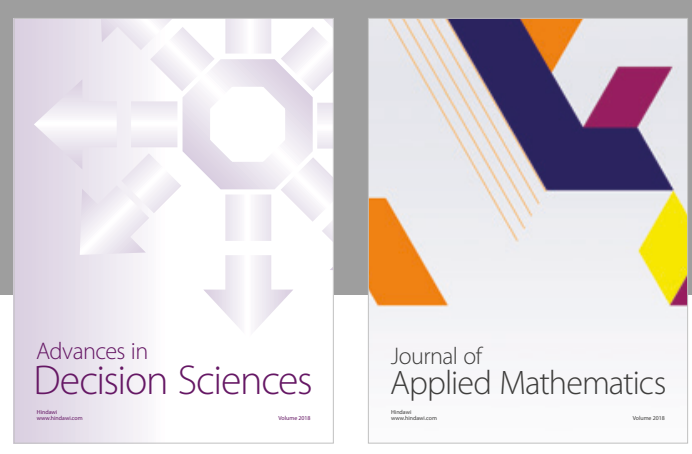

Journal of

Applied Mathematics
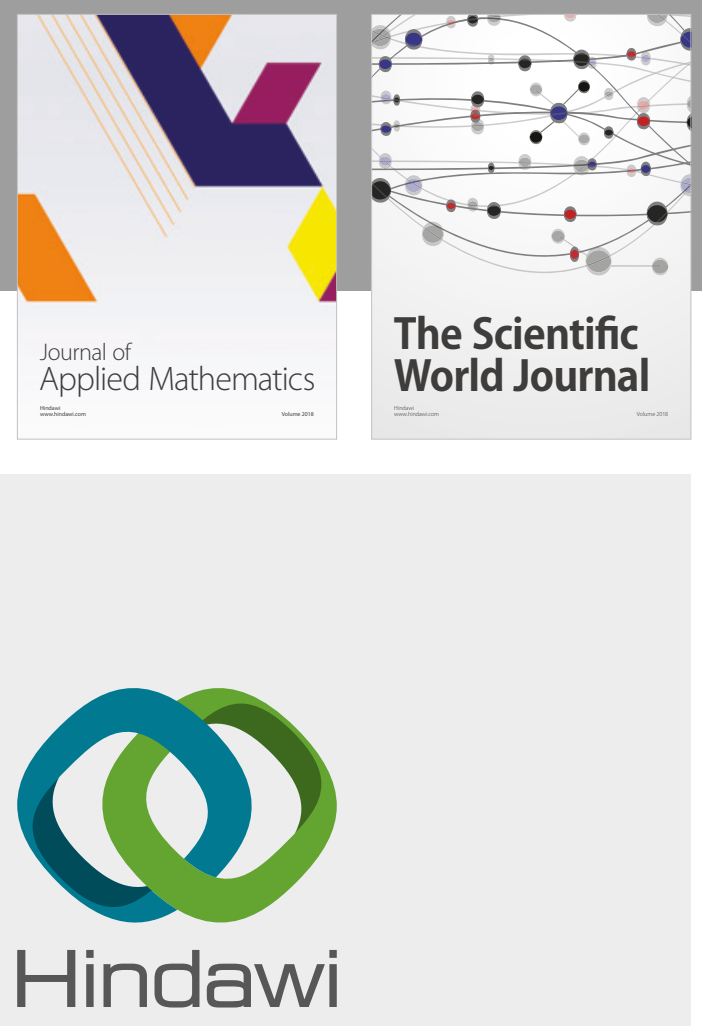

Submit your manuscripts at

www.hindawi.com

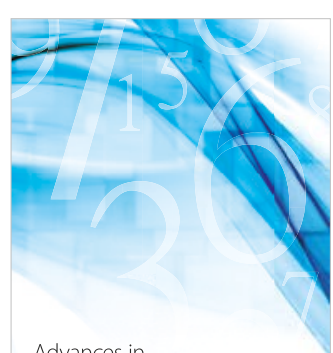

Advances in
Numerical Analysis
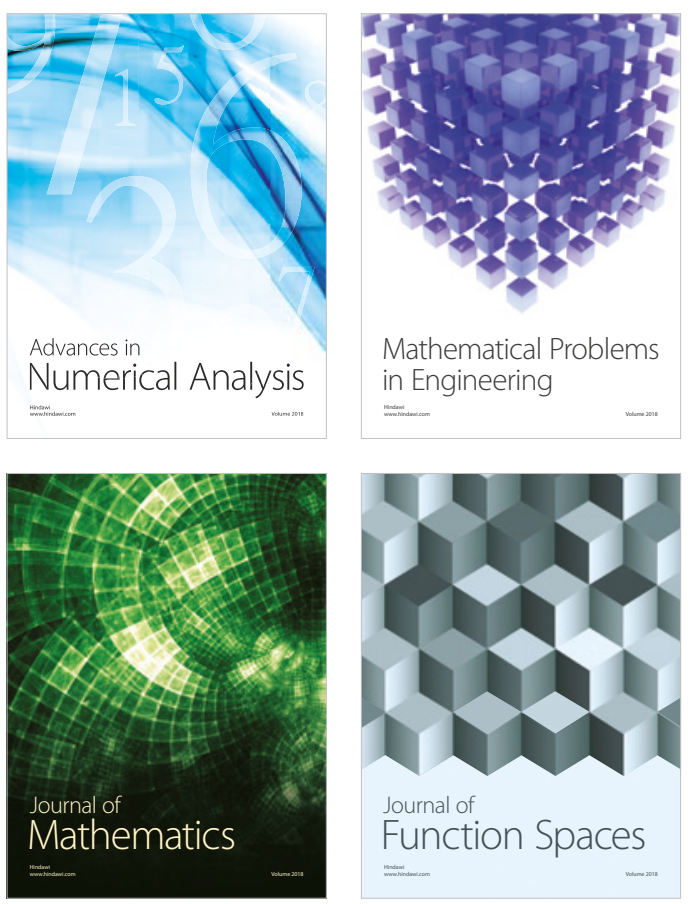

Mathematical Problems in Engineering

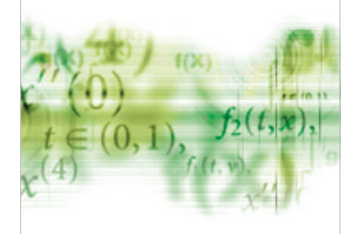

International Journal of

Differential Equations

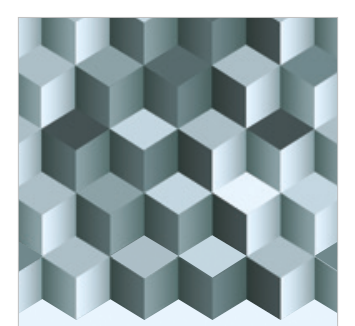

Journal of

Function Spaces

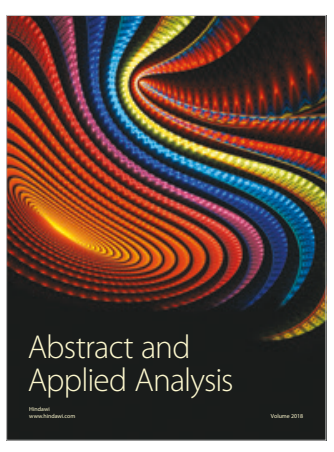

The Scientific

World Journal

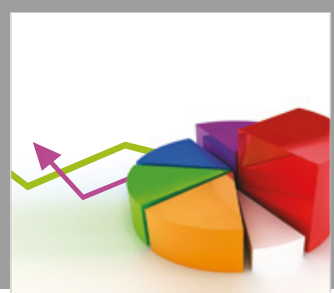

Journal of

Probability and Statistics
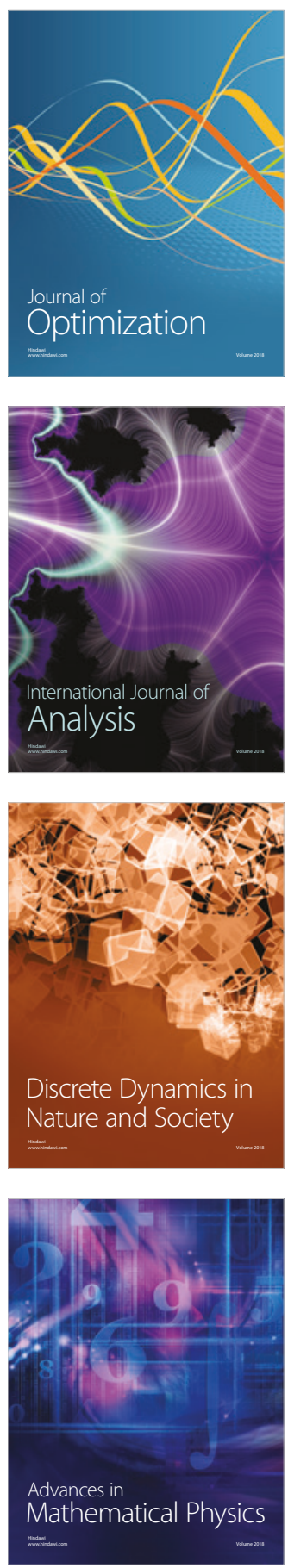